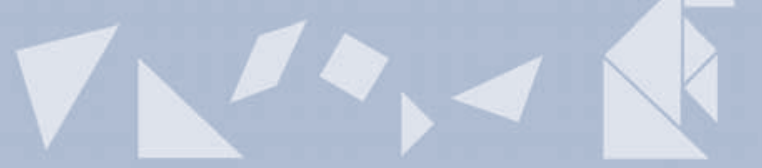

RELATO dE PRÁTICA: PROJETO CRIANÇA

\title{
Uma experiência formativa
}

Ana Luíza Mendes Borges

JOSÉ HAMILTON MARUXO JÚNIOR

Sônia Maria de Oliveira Nudelman*

A escola pública, como se sabe, sempre quer o sucesso dos seus alunos. Por isso, está atenta às suas próprias potencialidades e limites, busca alternativas com bom senso e prudência e discute possibilidades para atingir esse objetivo. Quando vê chances de ser apoiada em seus propósitos, torna-se parceira de experiências interessantes. Sabe que valem a pena mais ritmo, movimento, intensidade, trabalho coletivo, muita conversa, estudo e, principalmente, coragem para trilhar novos caminhos, se isso significa atingir seus propósitos.

É o que vem acontecendo com as escolas participantes do Projeto Criança, uma proposta para o ensino da leitura e da escrita, direcionada à $4^{\underline{a}}$ e $5^{\underline{a}}$ série do ensino fundamental, que alia o estudo da Língua Portuguesa a estratégias de teatro. 0 Projeto é resultado da parceria entre o Instituto Algar de Responsabilidade Social e o CENPEC, e vem promovendo a reorientação e a problematização de práticas escolares essenciais: leitura de livros literários, produção de textos pelas crianças, desenvolvimento de habilidades artísticas, entre outras.

Como se sabe, a avaliação da aprendizagem é também uma dessas práticas escolares. O seu objetivo é acompanhar o desenrolar do processo de ensino e aprendizagem, a fim de orientar intervenções pedagógicas consideradas necessárias, com o propósito de garantir a aprendizagem dos alunos. Um dos instrumentos que compõem a avaliação é a prova.

Provas podem ser elaboradas pelos próprios professores e demais membros da equipe escolar e aplicadas aos alunos ou , então, por organizações externas à escola, tais como institutos de pesquisa especialmente con-

* Ana Luíza Mendes Borges é cientista social (FFLCH-USP) e pesquisadora do Cenpec.

JOSÉ HAMILTON MARUXO JÚNIOR é mestre em Letras (FFLCH-USP) e pesquisador.

SÔNIA MARIA DE OLIVEIRA NUdELMAN é pedagoga (PUC-SP) e coordenadora do Projeto Criança, no Cenpec. tratados para esse fim, fundações e organizações nãogovernamentais, entre outros.

No primeiro caso, professores e alunos - os agentes do processo da aprendizagem - estão envolvidos na avaliação de forma imediata, isto é, sem a mediação de agentes externos à escola.

No segundo caso, há intervenção de agentes externos - seja na elaboração das provas, seja na sua aplicação, correção ou aferição de resultados.

Este relato descreve a experiência de elaboração de uma prova da qual participaram os professores e as escolas do Projeto Criança e o CENPEC, ou seja, envolveu agentes escolares imediatamente implicados na avaliação e agentes externos. Para se compreender como essa experiência aconteceu, faremos um breve histórico do Projeto e, em seguida, situaremos, dentro dele, o processo de elaboração da prova e sua aplicação. Por fim, apresentaremos alguns resultados alcançados com esta experiência.

\section{Breve histórico e objetivos do Projeto Criança}

O Projeto Criança existe há mais de uma década e é desenvolvido em 28 escolas das redes municipais de ensino de 15 cidades dos estados de Goiás, Mato Grosso do Sul, Minas Gerais e São Paulo. No segundo semestre de 2004, estabeleceu-se uma parceria entre o Instituto Algar de Responsabilidade Social e o CENPEC. Com a parceria consolidada, o Projeto Criança vem se transformando num projeto de formação em Língua Portuguesa e Arte-Educação para professores, com o objetivo de se desenvolver, ao longo de três anos (de 2005 a 2007), uma proposta para o ensino da leitura e da escrita que se valha do teatro como estratégia. Além disso, contamos com a participação direta dos gestores das escolas e de secretarias municipais.

Em 2005, foram desenvolvidas atividades para fomentar a leitura e o teatro nas escolas. No final de 2006 , foi pos- 

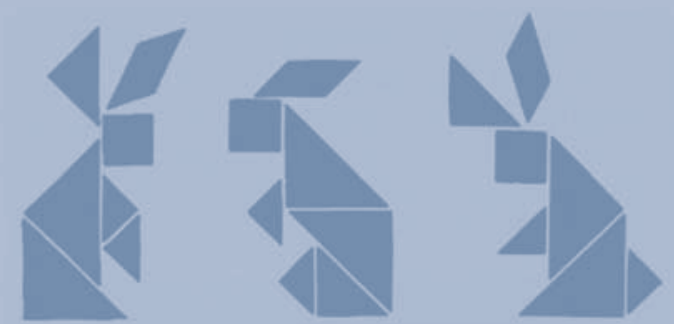

sível integrar o ensino da Língua Portuguesa ao da Arte, por meio do teatro, a partir de uma metodologia de trabalho que tem trazido bons resultados: as crianças lêem adaptações de boa qualidade de textos da literatura universal (Romeu e Julieta, Dom Quixote, Rei Artur e os Cavaleiros da Távola Redonda, Sonhos de uma noite de verão, O natal do avarento), contam e recontam as histórias lidas, opinam sobre elas, concordam ou não com os autores, conversam sobre suas leituras e escritas e ainda produzem livros e coletâneas de textos de sua própria autoria.

Foram realizadas, até o final de 2006 , aproximadamente 300 horas de formação continuada para cada um dos participantes, outras tantas de estudo e planejamento para difundir o projeto nas salas de aula de $4^{\underline{a}}$ e $5^{\underline{a}}$ séries, inúmeras outras de experimentação das ações nas classes, sem contar o tempo para registro e sistematização de conhecimentos, acompanhamento e avaliação, e celebração de conquistas.

Em 2007, pretende-se completar o ciclo de formação com a perspectiva de se avançar na construção de seqüências didáticas para aprendizagem da escrita, ancoradas no teatro, o qual fomenta a cooperação grupal, potencializa a concentração e a atenção, abre espaço para a participação, incentiva a oralidade e permite, por meio da expressão corporal, ampliar níveis de compreensão do que se lê e se escreve, de forma lúdica e prazerosa.

O ponto de partida e chegada são os alunos, seus conhecimentos e vivências culturais. Do universo com o qual convivem, foram escolhidas, como tema, as festas das quais participam nas suas escolas ou nas suas comunidades. A partir do repertório de experiência desses alunos, promove-se a interação com o novo, a aproximação com a leitura de livros que, se não forem lidos na escola, talvez não o sejam em lugar algum.

Dos aromas, das comidas, das brincadeiras, das músicas de festas - como a junina, a cavalhada, a congada, a folia de reis e o natal - são construídas ligas com os temas, personagens, enredos e com o ambiente das histórias lidas e encenadas. São criadas cenas para vivenciar as festas, para antecipar o conteúdo da leitura de textos literários, para checar o que se lê, para reviver a seqüência de ações dos personagens e, também, para contar, recontar e criar novas histórias.

Ler e escrever não se dissociam neste projeto. Do contexto das obras literárias, determina-se a seqüência didática da escrita. Se Romeu e Julieta trocam bilhetes e, também na festa junina, acontece o correio elegante, as crianças escrevem cartas e as trocam, como "Romeus" e "Julietas". Se Dom Quixote se envolve em mil aventuras, imortalizadas pela mão do seu autor-criador, as crianças também inventam seus heróis e escrevem suas aventuras. Se o Rei Artur reflete sobre quais estratégias usar para conquistar e apaziguar os povos que se rebelam contra seu poder, os meninos também escrevem, em seus diários de bordo, suas próprias reflexões sobre o esforço cotidiano que despendem para conquistar mais e novos conhecimentos.

A leitura dá a régua e o compasso da escrita. Oferece a indicação do gênero a ser trabalhado e, além disso, com o teatro, aquece o imaginário e fortalece repertórios. Prontos, os textos são novamente encenados, para que, em grupo, com a parceria dos alunos, se atue sobre a coerência da produção.

Esse trabalho se estabelece com o respeito necessário às práticas pedagógicas correntes nas várias escolas e cidades onde o Projeto Criança se instala. Por isso, procura cumprir a tarefa de conciliar os tempos de ação na urgência, característicos da escola, com os tempos da formação, a qual, à frente das questões mais rotineiras, constrói novos encaminhamentos e intervenções para as práticas de ensino em curso.

Não parte dos sistemas de ensino, embora conte com as autoridades locais para a criação de condições estruturais e logísticas que viabilizem sua implementação:

- constituição de acervo de livros da literatura universal;

- garantia da presença dos profissionais nos encontros de formação;

- estabelecimento de jornadas de trabalho que comportem tempos remunerados para a irradiação, acompanhamento e avaliação do projeto nas escolas.

É de adesão voluntária, mas demanda esforço individual de estudo, compromisso com a experimentação das atividades construídas nos encontros de formação e registro, em diário de bordo, da experiência que toma teatro como meio para ensinar a ler e a escrever com compreensão, autonomia e prazer.

Implica flexibilizar a gestão, ou seja, organizar grupos de relações horizontais que, em intenso trabalho coletivo, reflitam sobre as práticas de ensino da leitura e da escrita em curso, bem como promovam a apropriação de "competências leitoras e escritoras" entre todos os alunos das $4^{\underline{a}}$ e $5^{\underline{a}}$ séries. 
O Projeto compromete-se em acompanhar e avaliar os resultados de aprendizagem conquistados pelos alunos.

\section{0 processo de elaboração da prova}

Para nós, avaliar e acompanhar a implementação do projeto e medir seus resultados com base em alguns indicadores tem sido, mais do que uma tarefa, um compromisso. Na cultura dos parceiros do Projeto está a origem da decisão de sempre ter os olhos bem abertos para saber se os rumos previamente estabelecidos no plano do projeto estão sendo seguidos.

Para isso, desenvolvemos um modelo de avaliação composto pelos seguintes indicadores:

1. Gestão do projeto na secretaria:

- abrangência e infra-estrutura das escolas;

- acesso ao material pedagógico;

- carga horária do professor;

- presença dos profissionais nos encontros de formação.

2. Gestão do projeto na escola:

- organização dos horários de trabalho coletivo e dos horários de trabalho individual;

- formação de grupos horizontais de gestão do projeto;

- irradiação do projeto nas escolas;

- acompanhamento das práticas de ensino do projeto nas escolas;

- presença do Diário de Bordo;

- organização do espaço da escola.

3. Gestão do projeto na sala de aula:

- presença do Clube de Leitura;

- execução da seqüência de atividades (festa, leitura e escrita, mediadas por cenas);

- presença dos ateliês das seqüências didáticas de gêneros orais e escritos (leitura e escrita, mediadas por cenas);

- presença do Diário de Bordo (professor e aluno);

- acompanhamento das produções dos alunos.

4. Formação:

- grau de apropriação dos conceitos e das propostas de trabalho desenvolvidas na formação;

- grau de apropriação dos gêneros textuais desenvolvidos na formação (diário de bordo, roteiro de cenas, contos etc.);

- elaboração de seqüências de atividades e seqüências didáticas de gêneros orais e escritos.

\section{Aprendizagem:}

- grau de apropriação do uso das cenas como recurso para evidenciar compreensão na leitura - seqüência de ações, caracterização dos personagens, do tempo e do espaço;

- grau de apropriação de estratégias pessoais de leitura - leitura de indícios, antecipação e verificação;

- grau de apropriação de estratégias de leitura dramatizada;

- presença de escrita espontânea nos gêneros trabalhados;

- presença de parceria com os alunos no aperfeiçoamento dos seus textos escritos (cenas);

- grau de apropriação dos gêneros, entrevista e exposição oral.

Como forma de completar esse percurso avaliativo, a equipe propôs-se a elaborar um instrumento que desse um passo à frente em relação à matriz avaliativa do projeto, buscando obter dados relativos à aprendizagem dos alunos. A equipe do CENPEC responsável pelo Projeto ponderou que uma avaliação de aprendizagem poderia ser realizada de várias formas, mas, em larga escala, a escolha por provas seria eficiente e daria efetividade ao processo de avaliação.

Após discussões com os participantes, chegou-se à conclusão de que a prova se justificaria, em sua elaboração e aplicação, se, além de obter resultados de aprendizagem dos alunos, se transformasse em uma experiência de aprendizagem para a equipe escolar.

Com esse objetivo é que a prova foi elaborada e aplicada: além de mostrar resultados de aprendizagem dos alunos, ela poderia dar aos participantes e parceiros do Projeto a ocasião de aprender a elaborar um instrumento de avaliação em construção coletiva.

Durante os encontros de formação de 2005, quando os resultados do SAEB - Sistema Nacional de Avaliação da Educação Básica, Saresp - Sistema de Avaliação de Rendimento Escolar do Estado de São Paulo e Simave - Sistema Mineiro de Avaliação da Educação Pública eram apresentados para a discussão de aprendizagem, a equipe do CENPEC percebeu certa dificuldade dos professores em entender os dados, compreender o que significavam os indicadores e descritores dessas avaliações governamentais e, por vezes, uma certa resistência em aceitar que esses dados pudessem representar resultados de aprendizagem de seus alunos. Como estudantes 
A experiência de elaboração e aplicação de uma prova semelhante ao $S A E B$ poderia auxiliar os professores a compreender melhor essa forma de avaliar e, caso os resultados fossem semelhantes aos das avaliações governamentais, a experiência ainda poderia confirmar as indicações sobre a aprendizagem dos alunos.

que iam tão bem nas provas elaboradas por seus próprios professores poderiam ter resultados aquém do esperado nas avaliações governamentais, como o SAEB?

A experiência de elaboração e aplicação de uma prova semelhante ao SAEB poderia auxiliar esses profissionais a compreender melhor essa forma de avaliar e, caso os resultados fossem semelhantes aos das avaliações governamentais, a experiência ainda poderia confirmar as indicações sobre a aprendizagem dos alunos.

\section{Como a prova foi elaborada}

Uma das condições fundadoras do Projeto é a parceria. Seus produtos são sempre elaborados em parceria com os professores participantes da formação. Assim, no seu início, não contava com materiais e metodologia prontos a serem simplesmente utilizados pelos professores. Os encontros de formação tinham como objetivo a discussão de práticas pedagógicas do ensino da Língua Portuguesa e da gestão escolar, e os produtos das formações eram testados pelos professores em suas aulas. Esse modo de trabalho foi aplicado à elaboração da prova.

No início de 2006, as escolas e secretarias municipais de educação participantes do Projeto Criança foram consultadas sobre a sugestão do Instituto Algar de elaboração e aplicação de uma prova. A sugestão foi aceita e a equipe do CENPEC passou a definir estratégias para elaborar essa prova em parceria com os participantes da formação.
Construir uma prova a 600 mãos - há aproximadamente 300 profissionais que participam das formações do Projeto - não é uma tarefa muito fácil. Mas não poderia ser feita de outra maneira. Como sustentar o princípio da participação e da construção coletiva de uma proposta se se chegasse às escolas com uma prova pronta? Foi necessário tornar participativa a formulação do instrumento de avaliação, com todas as implicações que isso pudesse acarretar.

Durante as videoconferências, realizadas em fevereiro e março de 2006, foram definidos alguns critérios de elaboração da prova, a saber:

- deveria ser feita de forma coletiva, em função da natureza do Projeto e dos objetivos a que se propunha (transformar-se numa experiência de aprendizagem para professores e profissionais do (ENPEC);

- deveria medir habilidades de leitura e de escrita ligadas às atividades desenvolvidas no Projeto Criança. Por isso, restringir-se-ia a avaliar estas habilidades ligadas aos gêneros narrativos;

- seus resultados deveriam ser analisados com os outros indicadores de avaliação do projeto;

- o SAEB, sendo a única avaliação realizada em todos os estados onde o projeto acontece, serviria como modelo.

Para dar início às atividades de 2006 , em função de haver muitos participantes novos no Projeto, o CENPEC enviou às escolas um questionário para obter informações sobre o perfil desses participantes. Todos o preencheram. Já sabendo que a prova deveria ser elaborada, nele constava a seguinte questão:

"Se você fosse elaborar uma prova de leitura e escrita para seus alunos, qual(is) texto(s) utilizaria?”

Diversas sugestões foram apresentadas. Chamounos a atenção a uniformidade de gêneros textuais apresentados:

- $22 \%$ das sugestões eram fábulas;

- $18 \%$, contos de fadas;

- $17 \%$, textos informativos;

- $15 \%$, contos de aventura;

- $10 \%$, poemas;

- $18 \%$, outros gêneros (histórias em quadrinhos, crônicas, romance, auto-ajuda).

Dessas sugestões, foram excluídos os textos informativos, os poemas e os outros, pois os textos-base da prova deveriam ser narrativos. Assim, ficamos com fábulas, contos de fadas, contos de aventura. 


\section{MN}

0 efeito mais significativo, já perceptivel durante os encontros de formação realizados no segundo semestre de 2006, foi o fato de os professores terem começado a se preocupar com os resultados das avaliações oficiais, como o SAEB e a Prova Brasil. Além disso, mostraram-se muito mais prontos a interpretá-los à luz de suas práticas docentes, passando a reconhecê-los como válidos. A rejeição surgida no grupo de professores, no início do Projeto Criança, em relação à análise de dados provenientes das avaliações governamentais, já não se colocava no grupo de educadores do Projeto Criança.

Nossa hipótese inicial era a de que os resultados apresentariam um desempenho médio dos alunos em cada uma das habilidades (superior a $60 \%$ ), o que se confirmou a partir dos dados a seguir:

- $69,1 \%$ dos alunos reconhecem e identificam os elementos da narrativa;

- $63,9 \%$ reconhecem e identificam o conflito que gera a narrativa;

- $72,4 \%$ reconhecem o tema do texto;

- $79,1 \%$ identificam e localizam uma informação explícita no texto; e

- $64 \%$ inferem uma informação implícita no texto. No entanto, é importante salientar que esses dados requerem análises mais aprofundadas, que estabeleçam as relações necessárias entre eles e os outros indicadores, acima citados. Mesmo assim, já promovem significado para os professores, que se sentem mais responsáveis por encaminhá-los e, por isso, comprometidos com a estruturação de novas estratégias de melhoria da aprendizagem dos alunos.

A avaliação fortaleceu a importância do ensino do texto narrativo para os professores. No início do Projeto, muitos deles tinham dificuldade em compreender os elementos e a estrutura textual da narrativa, assim como a identificação dos gêneros narrativos. A discussão em torno das "habilidades leitoras" para o texto narrativo mudou essa situação.

Isso se refletiu indiretamente até nas escolhas dos professores: no início do ano, os textos sugeridos por eles, para o trabalho com os alunos e até para a elaboração da prova, restringiam-se a narrativas curtas e a gêneros de pouca complexidade, como as fábu- las e os contos de fadas. No fim do ano, as opções de leitura, efetuadas pelos mesmos professores, incluíam textos mais longos e complexos, o que indica que eles passaram a acreditar que seus alunos seriam capazes de ler textos mais longos do que aqueles que sugeriram antes.

Durante o processo de elaboração da prova, ficou evidente, para a equipe do CENPEC, a necessidade urgente de o projeto ter uma transposição mais direta para a sala de aula, com a explicitação clara de modelos que pudessem ser recriados nas classes. Nesse sentido, a própria prova serviu como modelo para outras situações de avaliação, das quais se pôde ter notícia ao longo do ano, no acompanhamento das atividades do Projeto (professores participantes do Projeto se aventuraram a criar suas provas a partir de habilidades de leitura e escrita).

Assim sendo, haver elaborado uma prova de forma participativa se tornou uma grande experiência de aprendizagem para todos: participantes e equipe do CENPEC. Contribuiu para que a avaliação pudesse ser mais bem apropriada pelos professores e para criar uma mentalidade propositiva em relação à parceria entre professores e alunos nesse processo.

\section{Notas}

1 Os três autores compõem a equipe do Projeto Criança no CENPEC.

20 Instituto Algar de Responsabilidade Social está ligado às empresas do Grupo Algar, com sede em Uberlândia, Minas Gerais, e financia projetos educacionais, dos quais participam escolas públicas dos municípios onde as empresas do Grupo atuam. Esses projetos têm assessoria educacional de ONGs COMO o CENPEC.

3 A videoconferência é um dos instrumentos do Projeto Criança para a gestão compartilhada: em 2005 , mensalmente, todos os participantes do projeto se reuniam, via videoconferência, com o CENPEC. Durante essas reuniões, acompanhavam-se as ações dos professores e também se tomavam decisões no âmbito da gestão. Estas videoconferências aconteciam alternadamente com os encontros mensais de formação, de modo que, quinzenalmente, a equipe do Cenpec encontrava-se com os participantes do Projeto. Em 2006, esse esquema de reuniões se manteve, alternando encontros de formação presenciais e videoconferências. Graças a isso, foi possível a elaboração da prova durante fevereiro e março de 2006.

4 Segundo alguns pesquisadores (ver: Brandão; Spinillo. Aspectos gerais e específicos na compreensão de textos. Universidade de Pernambuco, 1998. Disponivel em: 〈http://www.scielo.br/scielo.php?script=sci_ arttext\&pid=S0102-79721998000200006\&lng=pt\&nrm=iso.htm»), a compreensão pode ser avaliada pelo reconto - paráfrase - ou por questões baseadas em habilidades específicas. No primeiro caso, considera-se o texto como um todo, e se avalia a compreensão em relação às informações nele contidas; no segundo, as questões permitem focalizar informações e partes específicas do texto. 
125 